Mycologia, 104(6), 2012, pp. 1502-1509. DOI: 10.3852/12-072

(C) 2012 by The Mycological Society of America, Lawrence, KS 66044-8897

\title{
A new Cortinarius of section Calochroi (Basidiomycota, Agaricomycetes) from Mediterranean Quercus woodlands (Italy)
}

Alfredo Vizzini ${ }^{1}$

Dipartimento di Scienze della Vita e Biologia dei Sistemi, Università di Torino, Viale P.A. Mattioli 25, I-10125 Torino, Italy

Marco Clericuzio

Dipartimento di Scienze e Innovazione Tecnologica, Università del Piemonte Orientale, Via T. Michel 11, I-15121 Alessandria, Italy

Fabrizio Boccardo

Via Filippo Bettini 14/11, I-16162 Genova, Italy

Enrico Ercole

Dipartimento di Scienze della Vita e Biologia dei Sistemi, Università di Torino, Viale P.A. Mattioli 25, I-10125 Torino, Italy

Abstract: A new species of Cortinarius, C. flavoaurantians sp. nov., is described from Italian Quercus woods based on both morphological and ITS rDNA data. This taxon is characterized by a yellowish pileus and cortina, a white universal veil and a pileipellis that reacts yellow-orange with $\mathrm{KOH}$. Illustrations of the key micromorphological features and fresh basidiomata in situ are provided. Closely related species are discussed.

Key words: Agaricales, biodiversity, Cortinariaceae, Cortinarius calochrous, taxonomy

\section{INTRODUCTION}

The /calochroid clade is a species-rich lineage of Cortinarius (Pers.) Gray (Cortinariaceae R. Heim ex Pouzar, Agaricales Underw.), mainly distributed across the forested northern hemisphere and formerly classified in subgenus Phlegmacium (Fr.) Trog (now regarded as an artificial polyphyletic group; Garnica et al. 2003, 2005, 2009; Peintner et al. 2001, 2004; Frøslev et al. 2005; Harrower et al. 2011). It comprises no less than 100 species occurring throughout Europe, Central and North America (Frøslev et al. 2007; Garnica et al. 2009, 2011; Harrower et al. 2011), characterized by conspicuous, brightly pigmented basidiomes, a dry stipe with a rounded to abruptly bulbous (marginate) base, a pileipellis with a well developed gelatinous matrix, and the presence of pigments (in pileus and stipe surface and context), which often change color with the application of $\mathrm{KOH}$.

Submitted 5 Mar 2012; accepted for publication 18 Apr 2012.

${ }^{1}$ Corresponding author. E-mail: alfredo.vizzini@unito.it
This clade includes sections Calochroi M.M. Moser \& Horak ("calochroid" taxa sensu Frøslev et al. 2007, without anthraquinoid pigments) and Fulvi M.M. Moser ("fulvoid taxa" sensu Frøslev et al. 2007, with anthraquinoid pigments) as traditionally circumscribed by Melot (1990), Brandrud (1998) and Brandrud et al. (1989-1998), and is regarded as one of the most difficult taxonomic groups in the Agaricales (Frøslev et al. 2007).

Recently seven major monophyletic lineages were recognized by Garnica et al. (2009) within the / calochroid clade based on a combined multilocus phylogenetic analysis, namely Calochroi (hereafter indicated as Calochroi s.s.), Caroviolacei, Dibaphi, Elegantiores, Napi, Pseudoglaucopodes and Splendentes. Within Calochroi s.s. several species are rare and have limited distributions, often growing on calcareous soils and mainly associated with deciduous trees belonging to Betulaceae (Corylus, Carpinus, Ostrya) and Fagaceae (Castanea, Fagus, Quercus); a few species are known to be associated with Pinaceae (Garnica et al. 2009). Most species are characterized by bright (pink-red) reactions of the basidiome surface to $\mathrm{KOH}$, usually indicating the presence of sodagnitins (Sontag et al. 1999; Frøslev et al. 2007), lilac lamellae, presence of abundant and evident universal veil remnants on pileus and stipe, absence of anthraquinoid pigments (Gill and Steglich 1987; Frøslev et al. 2007), and an eight bp length indel in the intron 2 portion of the RPB1 gene (Garnica et al. 2009).

To date, species circumscriptions have relied on morphological characters, but a confident specific assignment can hardly be made on the basis of morphological data alone, even if both micro- and macroscopic characters are taken into account. Variability and/or overlapping of many important characters, such as basidiome colors, spore dimensions, host-tree specificity, and even chemical reactions with $\mathrm{KOH}$, all lead to problematic and conflicting taxonomic treatments. Recently analyses of genomic sequences (ITS, RPB1-RPB2 and D1/D2 regions of the nucLSU rDNA) have provided considerable aid (Frøslev et al. 2006, 2007; Ortega et al. 2008; Garnica et al. 2009). The number of species recognized to date based on phylogenetic analyses of gene sequences (Frøslev et al. 2006, 2007; Garnica et al. 2009) has proved to be comparable or larger than that previously proposed even by authors such as Bidaud et al. (2001) who employ a narrow 
morphological species concept. However species recognized by means of a morphological species concept (morphospecies) and those recognized by applying a phylogenetic species concept (phylospecies) often do not overlap and in many cases a single name was applied to different phylogenetic species, or vice versa different names were given to the same phylogenetic species. It is evident that a correct, phylogenetic taxonomic framework can be achieved only by using both morphological and molecular markers; in Calochroi this goal is still far from reach.

During fieldwork in Quercus woodlands in Liguria (NW Italy), collections of a striking Cortinarius of Calochroi s.s with a white universal veil, yellowish cortina, and a peculiar yellow-orange reaction of the pileus surface to $\mathrm{KOH}$, were made. Based on both morphological and ITS rDNA analyses, the taxon is described as a new species.

\section{MATERIALS AND METHODS}

Morphology.-Macromorphological features were described from fresh specimens. Microscopic elements were described from herbarium material rehydrated in $3 \% \mathrm{KOH}$ and stained in Congo red. The localization of the pigments in the pileipellis elements was observed from water mounts of dried material. Basidiospore measurements are based on means of 120 spores in $3 \% \mathrm{KOH}$ from three collections. Only mature, normally developed and non-aberrant spores from spore prints (e.g. from the cortina remnants on the stipe) were measured. The width of each basidium was measured at the widest part, and the length was measured from the apex (sterigmata excluded) to the basal septum. These abbreviations are used: $\mathrm{L}=$ number of entire lamellae; 1 = number of lamellulae between each pair of entire lamellae; $\mathrm{Q}=$ the quotient of length and width of the spores in side view; $\mathrm{Qm}=$ average quotient. Alkaline reactions were produced by adding a drop of potassium hydroxide $(10 \% \mathrm{KOH})$ to surfaces (pileipellis, stipitipellis, bulbipellis) and context (KOH drop test), and observed on young as well as on mature and dried specimens. Color terms in capital letters (e.g. Pale Orange-Yellow) are those of Ridgway (1912). Author citations follow the Index Fungorum Authors of Fungal Names (http://www. indexfungorum.org/authorsoffungalnames.htm). Herbarium abbreviations are according to Thiers (2011). The type material is kept in GDOR (Herbarium of the Museo Civico di Storia Naturale Giacomo Doria, Genoa, Italy).

DNA extraction, PCR amplification and DNA sequencing.Genomic DNA was isolated from $1 \mathrm{mg}$ of a dried herbarium specimen from three collections (GDOR 2528, GDOR 2529, GDOR 2530) with the DNeasy Plant Mini Kit (QIAGEN, Milan, Italy) according to the manufacturer's instructions. Universal primers ITS1F/ITS4 were used for the ITS region amplification (White et al. 1990; Gardes and Bruns 1993). Amplification reactions were performed in a PE9700 thermal cycler (Perkin-Elmer, Applied Biosystems) following Vizzini et al. (2011). PCR products were purified with the AMPure XP kit (Beckman) and sequenced by MACROGEN Inc. (Seoul, Republic of Korea). The sequences were assembled and edited with the phred/phrap/consed software suite. Sequences were submitted to GenBank (http://www.ncbi. nlm.nih.gov/genbank/), and accession numbers are reported in Material studied and in Figs. 1, 2; the alignments and phylogenetic trees are available at TreeBASE (www.treebase. org) under accession number 12646.

Sequence alignment and phylogenetic analysis.-The sequences were checked and assembled with Geneious 5.3 (Drummond et al. 2010) and compared to those available in GenBank database with the BLASTn algorithm. Based on the BLASTn results, Cortinarius sequences were selected according to the outcomes of recent phylogenetic studies on Cortinaris sect. Calochroi (Frøslev et al. 2007; Ortega et al. 2008; Garnica et al. 2009). Alignments were generated with MAFFT (Katoh et al. 2002) with default conditions for gap openings and gap extension penalties. The alignment was imported into MEGA 5.0 (Tamura et al. 2011) for manual adjustment. The best-fit models were estimated by both the Akaike information criterion (AIC) and the Bayesian information criterion (BIC) with jModelTest 0.1.1 (Posada 2008) to provide a substitution model for the alignment. The GTR + G substitution model was chosen for the analyses. Phylogenetic analyses were performed with maximum likelihood (ML) and Bayesian inference (BI) approaches. Three Cortinarius species belonging to sect. Elegantiores (C. elegantior [AY174850], C. eufulmineus [EF014257], C. majusculus [EU655682]) were used as outgroup taxa in both analyses. ML estimation was performed through RAxML 7.0.4 (Stamatakis 2006) with 1000 bootstrap replicates (Felsenstein 1985) with the GTRGAMMA algorithm to perform a tree inference and search for a good topology. Support values from bootstrapping runs (MLB) were mapped on the globally best tree with the $-\mathrm{F}$ A option of RAxML and $-\mathrm{x} 12345$ as a random seed to invoke the novel rapid bootstrapping algorithm. BI of phylogeny with Monte Carlo Markov chains (MCMC) was carried out with MrBayes 3.1.2 (Huelsenbeck and Ronquist 2001). Four incrementally heated simultaneous MCMC were run 10000000 generations. Trees were sampled every 1000 generations, resulting in an overall sampling of 10001 trees. The first 2500 trees (25\%) were discarded as burn-in. Burn-in value was determined with Tracer 1.5 (Rambaut and Drummond 2007). For the remaining trees, a majority rule consensus tree showing all compatible partitions was computed to obtain estimates for Bayesian posterior probabilities (BPP). Branch lengths were estimated as mean values over the sampled trees. Only MLB more than $50 \%$ and BPP values more than 0.70 are reported in the resulting trees (FIGS. 1, 2). Pairwise percent identity values of ITS sequences were calculated with MEGA 5.0 (Tamura et al. 2011).

\section{RESUlts}

Phylogenetic analyses. - The amplification of the ITS regions was successful for the three specimens, 


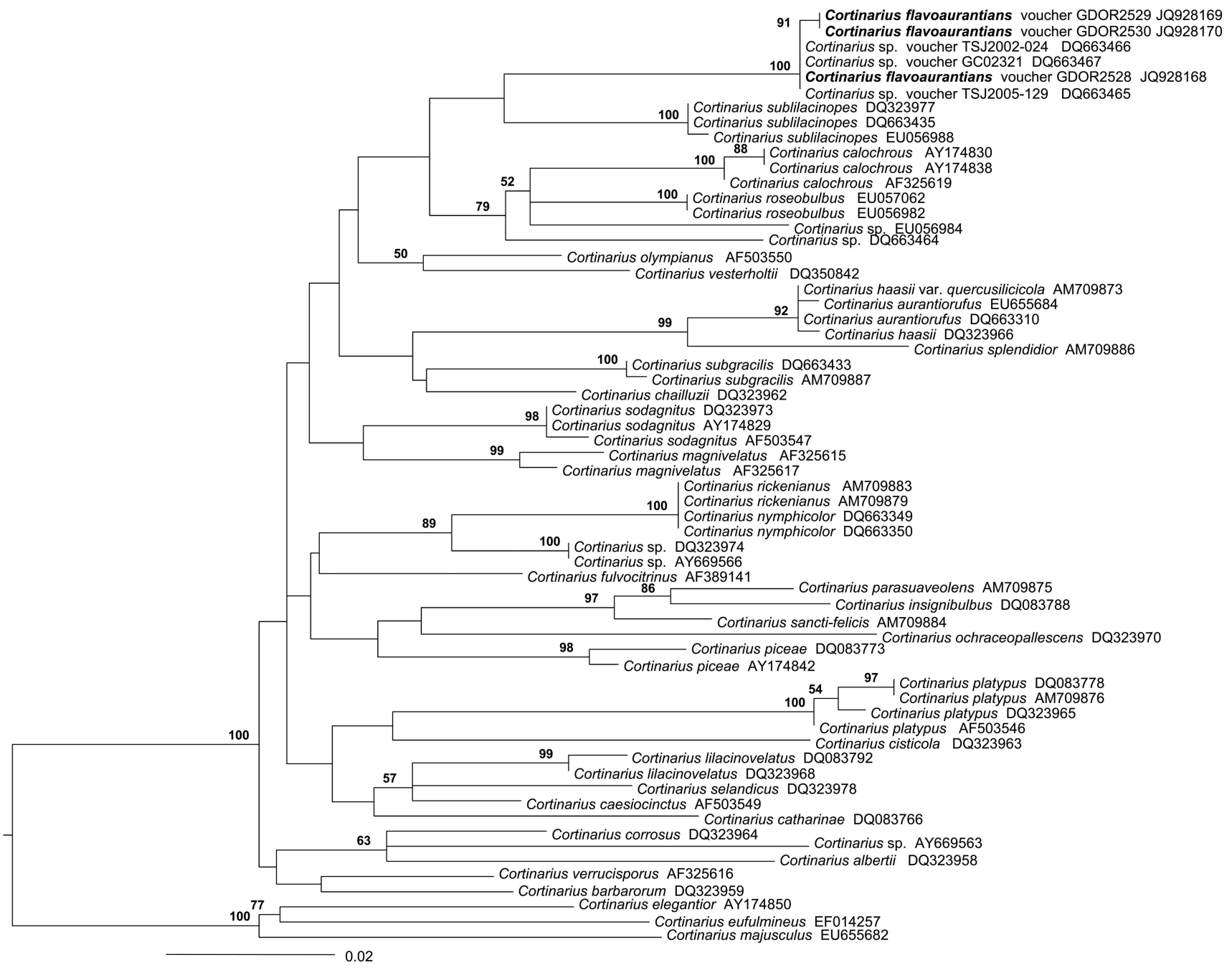

FIG. 1. Maximum likelihood phylogram obtained from the ITS (ITS1-5.8S-ITS2) sequence alignment of Cortinarius spp. (sect. Calochroi s.s.). C. elegantior, C. eufulmineus and C. majusculus (sect. Elegantiores) were used as outgroup taxa. MLB values greater than $50 \%$ are above branches. Bar $=$ number of substitutions per site.

yielding a PCR product of about $680 \mathrm{bp}$. The ITS data matrix comprised a total 62 sequences (including 59 from GenBank). This dataset is $646 \mathrm{bp}$ long and contains $197(30.5 \%)$ variable sites. Of these, 128 $(19.8 \%)$ are parsimony informative.

In both ML and Bayesian analyses, our three Cortinarius flavoaurantians sequences cluster with three sequences belonging to unidentified Cortinarius collections (GC02321, TSJ2002-024, TSJ2005-129), forming a well supported clade (MLB $100 \%$ and BPP 1; FIGS. 1, 2). These three unidentified collections correspond to the Cortinarius sp. 7 in Frøslev et al. (2007). The pairwise percent identity value of the entire clade is 99.9. The ML analysis placed these six sequences in a weakly supported sister clade to $C$. sublilacinopes (MLB $<50 \%$ ), while in the BI tree they are sister to a clade consisting of C. calochrous, $C$. roseobulbus and two Cortinarius sp. $(<0.70 \mathrm{BPP})$. In the BI tree, the clade composed of C. flavoaurantians, C. calochrous, C. roseobulbus, C. sublilacinopes and five Cortinarius sp. is supported by 0.99 of BPP.

\section{TAXONOMY}

Cortinarius flavoaurantians Boccardo, Clericuzio \& Vizzini, sp. nov. FIGS. 3-5 Mycobank MB800140

It is characterized by an initial yellow-orange $\mathrm{KOH}$ reaction of pileus surface (becoming red-brown in a few minutes) in fresh basidiomata, bulbipellis and stipitipellis not reacting with $\mathrm{KOH}$, white universal veil remnants, a yellowish partial veil, white mycelial strands and small amygdaliform spores $(<10 \mu \mathrm{m}$ on average).

Type: Italy, Liguria, Genoa, M. Portofino, 19/11/ 2011, leg. F. Boccardo, (GDOR 2529, Holotype). 


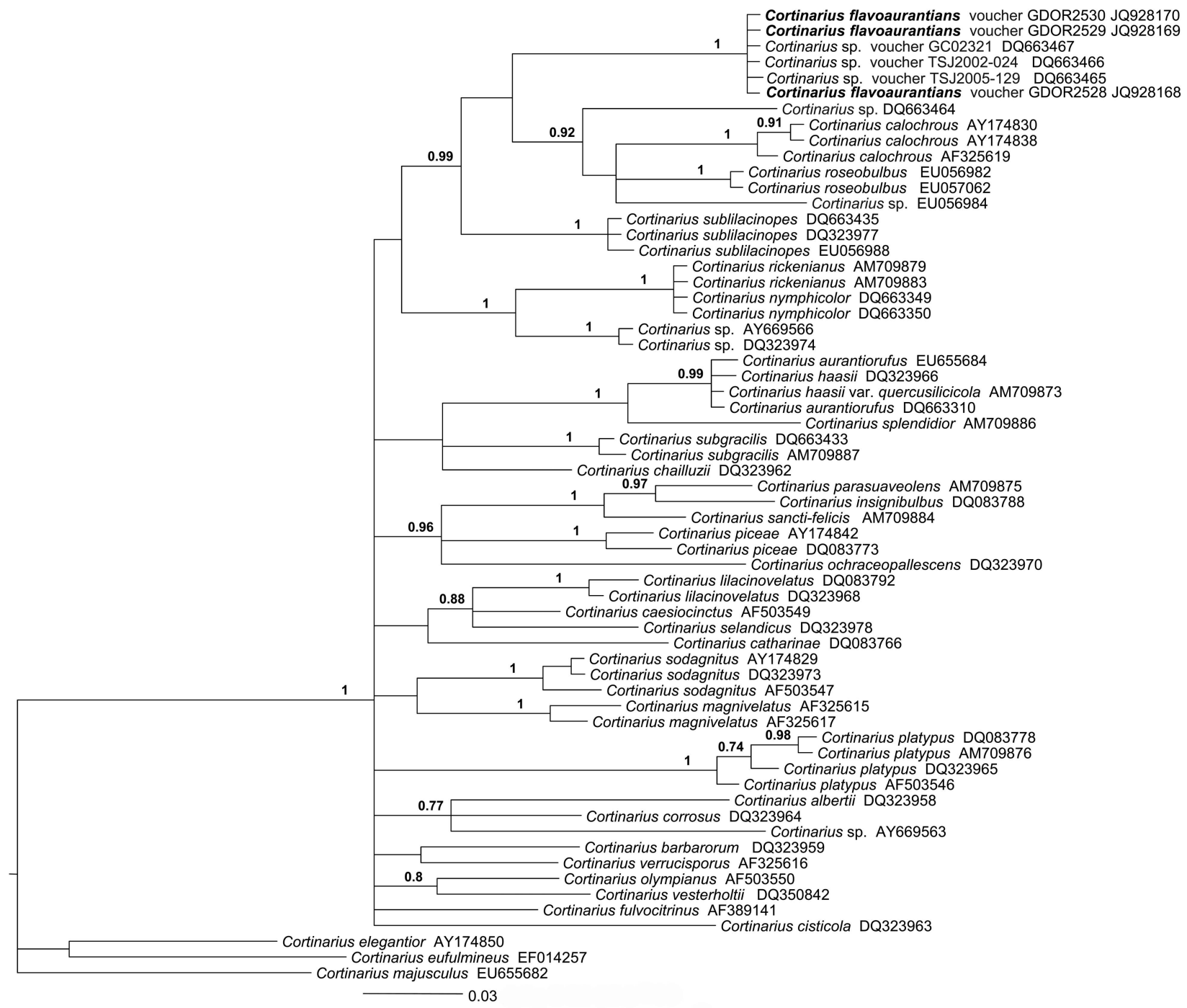

FIG. 2. Bayesian phylogram obtained from the ITS (ITS1-5.8S-ITS2) sequence alignment of Cortinarius spp. (sect. Calochroi s.s.). C. elegantior, C. eufulmineus and C. majusculus (sect. Elegantiores) were used as outgroup taxa. BPP values greater than 0.70 are given above branches. Bar $=$ number of substitutions per site.

Pileus 30-60 $\mathrm{mm}$ broad, initially convex, then plano-convex with an involute margin, finally slightly depressed at center with age; surface viscid, at first smooth, sometimes slightly wrinkled, light pale yellow (Pale Orange-Yellow, Maize Yellow), to ochraceous yellow (Buff-Yellow), soon spotted with reddish brown to rusty orange (Deep Chrome, Cadmium Yellow) \pm radial innate fibrils; universal veil remnants abundant on pileus surface, at first as white, large thin patches, sometimes with a few fugacious violaceous hues (Pale-Blue Violet) (Figs. 3b, 4), then bruising orange-brown (Orange Rufous, Xanthine Orange, Mars Orange) and visible as small scales. Lamellae emarginate, medium crowded $(\mathrm{L}=60-80,1=[0] 1$ 2 [3]), violaceous pink to light purplish at the beginning (Pallid Violet-Blue, Pallid Blue-Violet,
Pallid Bluish Violet, Pallid Violet), rapidly darkening to rusty brown with age (due to spore maturation); with a slightly crenulate edge. Stipe $20-70 \times 10-$ $20 \mathrm{~mm}$, stout, whitish to pale yellowish, usually showing pink-violet tinges (Pallid Violet-Blue, Pallid Blue-Violet) at apex, cylindrical, with a broad, flattened marginate bulb $(\times 20-35 \mathrm{~mm})$; universal veil remnants abundant on bulb surface, white, sometimes with a few fugacious scattered violet hues (Pale-Blue Violet); partial veil (cortina) abundant, yellowish; mycelial strands white. Context white, slightly pink-violaceous at stipe apex; odor weak, somewhat herbaceous; flavor mild but bitter in the pileus surface. Chemical reactions $10 \% \mathrm{KOH}$ on pileus surface of fresh basidiomes, at first dark yellow (Apricot yellow, Cadmium Yellow), in few seconds 

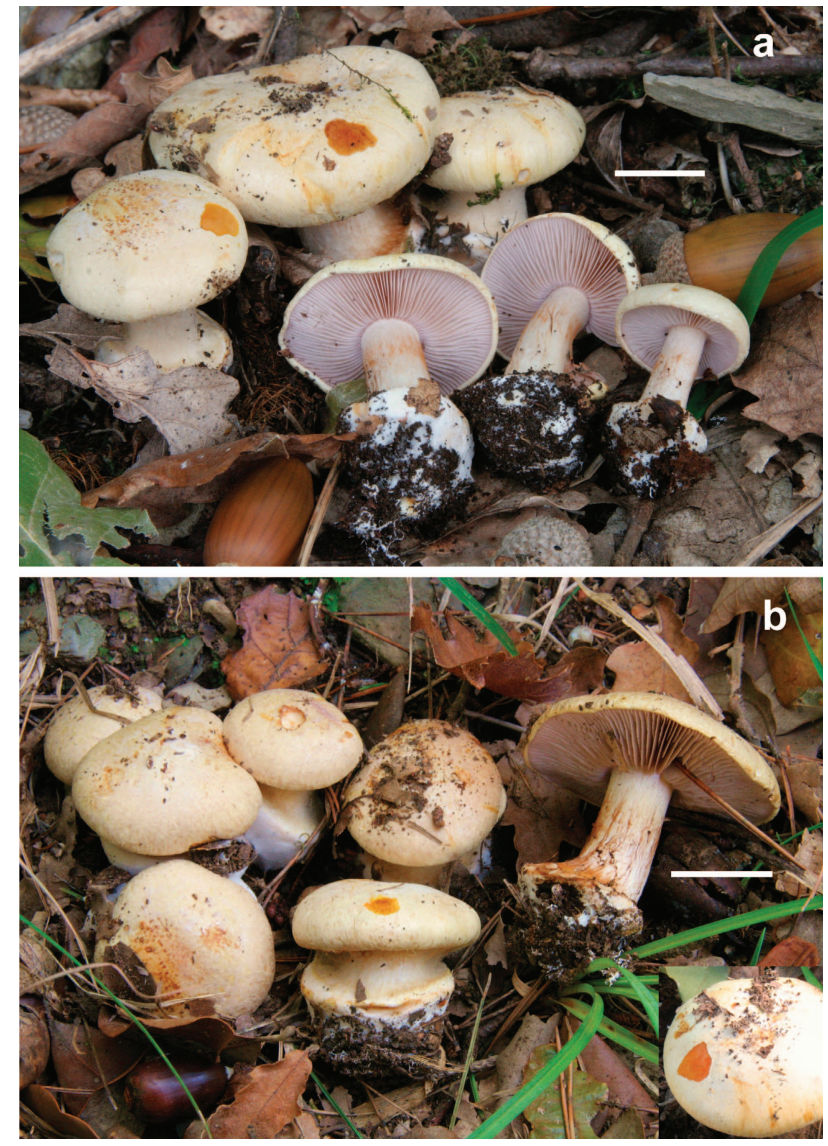

FIG. 3. Cortinarius flavoaurantians. a. Basidiomes (from GDOR 2529, holotype). b. Basidiomes with universal veil remnants with fugacious violaceous hues (from GDOR 2528). Color spots on pileus surface are due to $\mathrm{KOH}$ application $(10 \% \mathrm{KOH}$ drop test). Bars $=20 \mathrm{~mm}$.

orange-yellow, carrot orange (Cadmium Orange, Ochraceous Orange, Carnelian Red), then quickly oxidizing to red or reddish brown (Xanthine Orange, Tawny, Ferruginous) (FIG. 3a, b); weak or no reaction on bulbipellis, stipitipellis and context; $10 \% \mathrm{KOH}$ on pileus surface of dried basidiomes, red to reddish brown (Xanthine Orange, Tawny, Ferruginous).

Spores (8.2) 8.5-10.5(11.0) × 5.3-6.3(6.7) $\mu \mathrm{m}, 9.31$ $\times 5.89 \mu \mathrm{m}$ on average, $\mathrm{Q}=(1.36) 1.42-1.79(1.84)$, $\mathrm{Qm}=1.58$, regularly amygdaliform, more rarely elliptic-amygdaloid, never or rarely papillate-citriform, distinctly and coarsely verrucose (FIG. 5c, d); warts large, up to $1.5 \mu \mathrm{m}$ high, mainly isolated or slightly connected. Basidia clavate, four-spored, 30-35 $\times 8-9 \mu \mathrm{m}$, thin-walled and hyaline in $\mathrm{KOH}$; sterigmata up to 5-6 $\mu \mathrm{m}$ long; basidioles 20-30 $\times 6-8 \mu \mathrm{m}$ (FIG. 5b). Cheilocystidia and pleurocystidia not observed. Pileipellis (Fig. 5a, e) an ixocutis with some repent and ascending hyphae, made up of long, broad cylindraceous to fusoid elements, typically with distant septa; terminal elements 50-100(140) $\times 4$

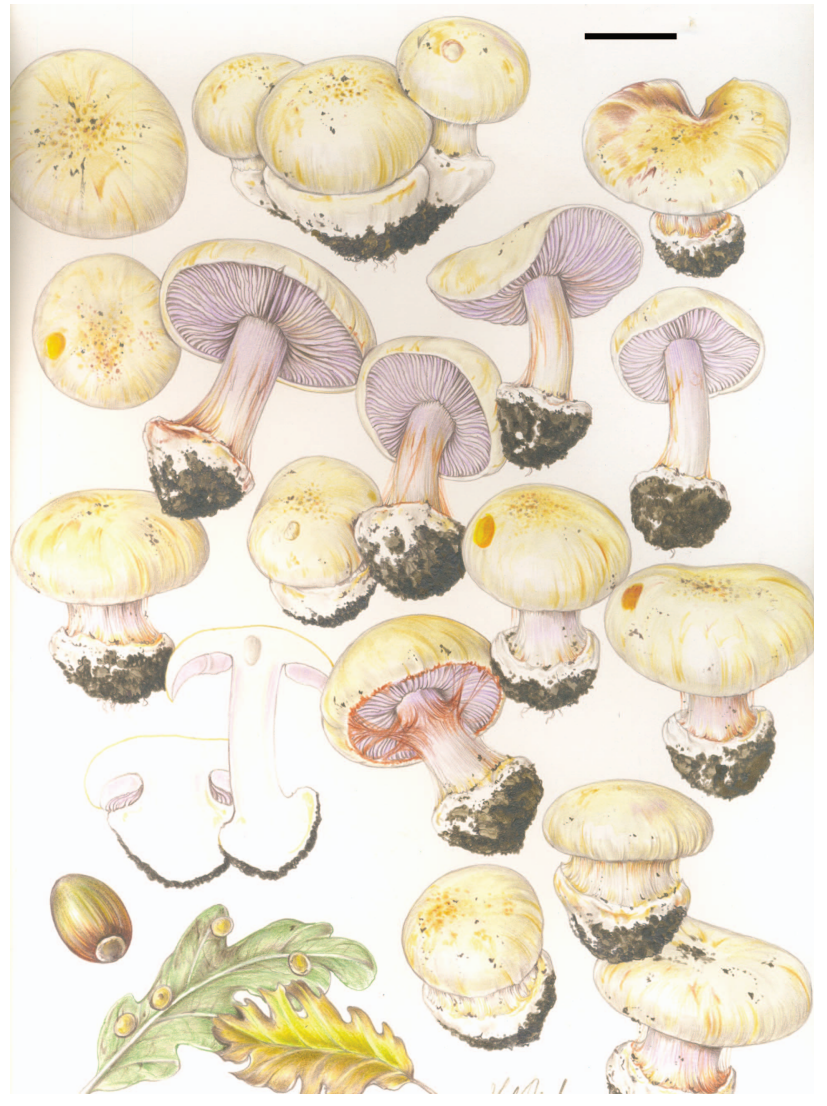

FIG. 4. Cortinarius flavoaurantians. Basidiomes (mixed specimens from GDOR 2528, GDOR 2529 and GDOR 2530). Drawing by F. Boccardo. Bar $=20 \mathrm{~mm}$.

6(7) $\mu \mathrm{m}$ with an obtuse to subcapitate apex, sometimes nipple-shaped (FIG. 5e); subpellis of interwoven, somehow short and broad hyphae, for example 35-60 $\times 5-10(15) \mu \mathrm{m}$. Pigment in outer hyphae mainly parietal, distributed as a thick golden yellow coating, often also more or less finely incrusting; in deeper hyphae parietal and coarsely encrusting; a more scattered cytoplasmatic yellow pigment is found as granules in some outer hyphae. Clamp connections frequent at all septa.

Etymology: The epithet, derived from the Latin words flavus (yellow) and aurantians (becoming orange), refers to the pileus and to the yellow-orange reaction of the pileus surface to $\mathrm{KOH}$.

Habitat: Mid- to late autumn (October, November), under broadleaf trees, mainly Quercus pubescens and Ostrya carpinifolia, on calcareous soil. Often growing thickly gregarious to (sub) caespitose.

Material studied: ITALY, Liguria, Genoa, Zoagli, about $300 \mathrm{~m}$ a.s.l., under $O$. carpinifolia, Q. pubescens and scattered Q. ilex, leg. F. Boccardo, 17 Nov 2011 (GDOR 2528, GenBank JQ928168); Genoa, M. Portofino, northeastern slope, about $500 \mathrm{~m}$ a.s.l., under $Q$. pubescens and $O$. carpinifolia, leg. F. Boccardo, 19 Nov 2011 (GDOR 2529, 
a

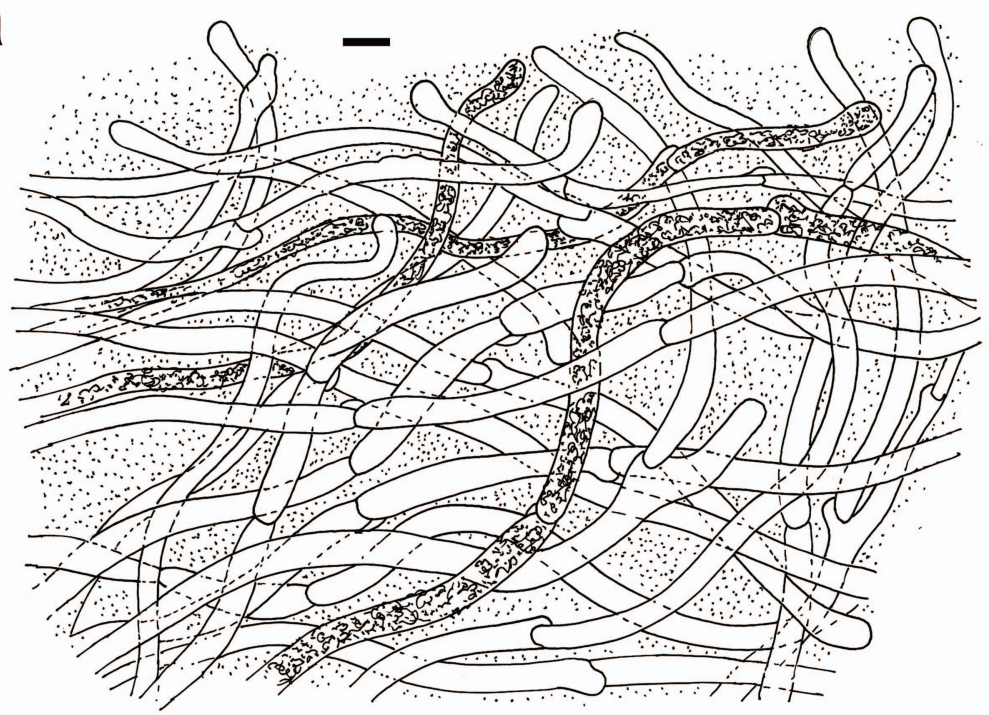

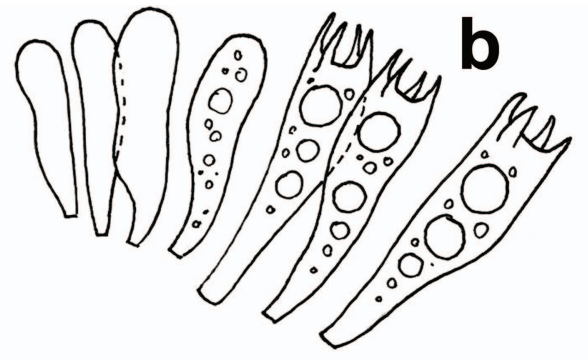

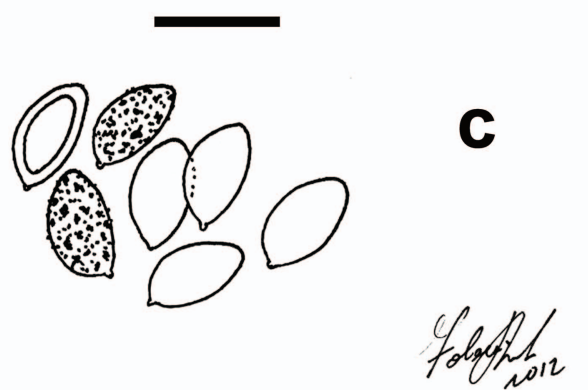

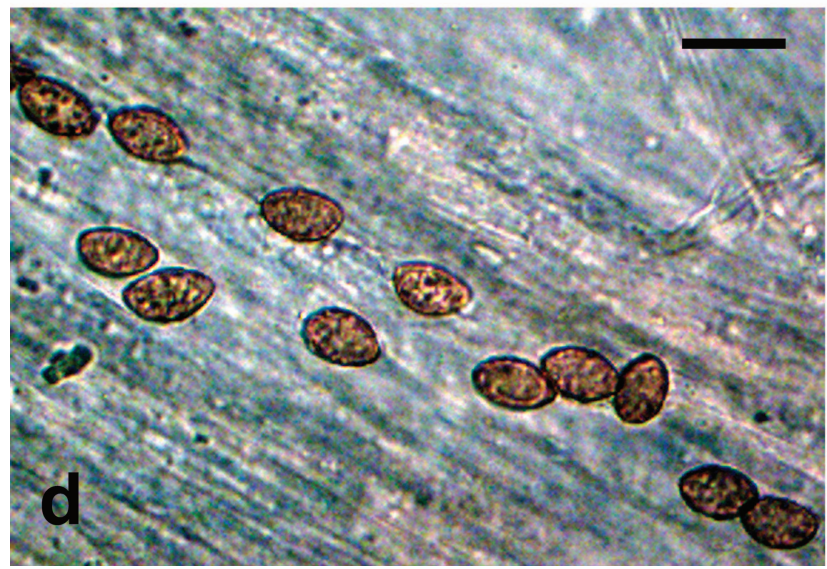

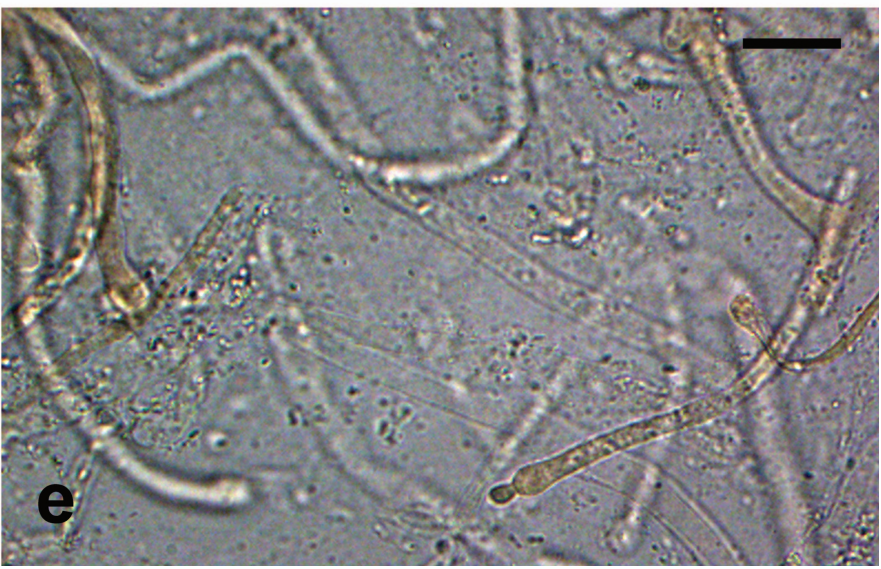

FIG. 5. Cortinarius flavoaurantians. Microscopic features (from GDOR 2529, holotype). a, e. Elements of the pileipellis. b. Basidia and basidioles. c, d. Spores. Bars $=10 \mu \mathrm{m}$.

GenBank JQ928169, HOLOTYPE); ibidem, but at about $400 \mathrm{~m}$ from the first collection site, leg. F. Boccardo, 23 Nov 2011 (GDOR 2530, GenBank JQ928170).

\section{Discussion}

Morphological data and phylogenetic analyses of ITS sequences support recognition of our collections as an independent species within Calochroi s.s., $C$. flavoaurantians.

As noted above, three unnamed collections (GC02321, Italy, Emilia-Romagna, under Q. pubescens and Q. cerris; TSJ2002-024, Czech Republic, under Carpinus and Quercus; TSJ2005-129, Spain, under $Q$. ilex and Q. pubescens), corresponding to Cortinarius sp. 7 in Frøslev et al. (2007), show a complete ITS sequence homology with C. flavoaurantians (pairwise percent identity value $=99.9$ ). Sequences from these three undetermined collections were considered close to either C. sublilacinopes and C. calochrous (Frøslev et al. 2007) or to C. calochrous and C. roseobulbus (Garnica et al. 2009). Future molecular analyses including additional gene sequences for increased resolution could provide additional evidence for considering these collections conspecific to C. flavoaurantians; at the moment data are insufficient to draw this conclusion.

Morphologically C. flavoaurantians belongs to a complex of species within Calochroi s.s. whose pilei are predominantly shades of yellow (pale yellow to ochraceous yellow, yellow-brown), and so finds its traditional placement close to species such as $C$. albovestitus Bidaud, C. calochrous (Pers.) Gray, C. catharinae Consiglio, C. chailluzii Frøslev \& T.S. Jeppesen, C. cisticola Frøslev \& T.S. Jeppesen, $C$. frondosophilus Bidaud, C. lilacinovelatus Reumaux \& Ramm, C. roseobulbus M.M. Moser, C. sublilacinopes Bidaud, Moënne-Locc. \& Reumaux, and C. subgracilis 
Moënne-Locc. (Moser and Ammirati 1997; Bidaud et al. 2001; Consiglio et al. 2004; Frøslev et al. 2006, 2007; Ortega et al. 2008). These yellow species do not form a monophyletic assemblage (FIGS. 1, 2; see also Frøslev et al. 2007 and Garnica et al. 2009) and, with the exception of C. calochrous, C. roseobulbus and C. sublilacinopes, they are not phylogenetically closely related to C. flavoaurantians (FIGS. 1, 2).

The new species is clearly distinguished from the other taxa by a unique combination of morphological characters including an initial yellow-orange $\mathrm{KOH}$ reaction of pileus surface, becoming red-brown in a few minutes (but a few hours after collection and in dry conditions the basidiomes may become reddish with $\mathrm{KOH}$, without showing the initial yellow-orange), bulbipellis and stipitipellis not reacting with $\mathrm{KOH}$, white universal veil remnants, a yellowish partial veil (cortina), white mycelial strands (rhizomorphs) and small amygdaliform spores $(<10 \mu \mathrm{m}$ on average). The $\mathrm{KOH}$ reaction probably mirrors the presence of a peculiar pigment set; to our knowledge, an (initially) yellow-orange $\mathrm{KOH}$ reaction on the pileus surface is rare in sect. Calochroi and so far known only for $C$. roseobulbus (Moser and Ammirati 1997).

ITS sequence analyses (FIGS. 1, 2) suggest a close affinity of our new species with $C$. calochrous, $C$. sublilacinopes and C. roseobulbus. C. calochrous is now considered to be almost exclusively associated with Fagus (Bidaud et al. 2001; Frøslev et al. 2006; Jeppesen et al. 2008) and differs in having a uniformly yellow pileus, bright, with no or little oxidation, a different alkaline reaction, namely red brown on pileus, and a yellow bulbipellis, mycelial strands and universal veil. C. sublilacinopes, mainly associated with Carpinus and Quercus, is distinguished by the blood red $\mathrm{KOH}$ reaction of the pileus surface and the presence of a yellow universal veil (Bidaud et al. 2001, Frøslev et al. 2006). Finally, C. roseobulbus, described from California under Quercus garryana and Notholithocarpus densiflora shares the peculiar (initial) yellow-orange $\mathrm{KOH}$ reaction of the pileipellis with $C$. flavoaurantians but differs by the yellowish universal veil and clearly pink bulbipellis and mycelial strands (Moser and Ammirati 1997).

\section{ACKNOWLEDGMENTS}

We thank Dr Samuele Voyron (University of Turin, Italy) for his helpful technical assistance.

\section{LITERATURE CITED}

Bidaud A, Moënne-Loccoz P, Reumaux P. 2001. Sous-genre Phlegmacium (Fr.) Trog, section Calochroi Moser \& Horak. Atlas Cortinaires 11:579-626.
Brandrud TE, Lindström H, Marklund H, Melot J, Muskos S. 1989-1998. Cortinarius Flora Photographica I-IV. Cortinarius HB, Matfors, Sweden. 146 p.

- 1998. Cortinarius subgen. Phlegmacium sect. Fulvichemotaxonomy versus morphological taxonomy. J JEC 0:4-9.

Consiglio G, Bidaud A, Antonini D, Antonini M, La Rocca S. 2004. Il genere Cortinarius in Italia III. Alcune specie interessanti della sezione Calochroi. Boll Ass Micol Ecol Romana 61:3-43.

Drummond AJ, Ashton B, Cheung M, Heled J, Kearse M, Moir R, Stones-Havas S, Thierer T, Wilson A. 2010. Geneious 5.3.

Felsenstein J. 1985. Confidence limits on phylogenies: an approach using the bootstrap. Evolution 39:783-791, doi: $10.2307 / 2408678$

Frøslev TG, Jeppesen TS, Læssøe T. 2006. Seven new calochroid and fulvoid species of Cortinarius. Mycol Res 110:1148-1160.

$[,-,-$, Kjøller R. 2007. Molecular phylogenetics and delimitation of species in Cortinarius section Calochroi (Basidiomycota, Agaricales) in $\mathrm{Eu}-$ rope. Mol Phylogenet Evol 44:217-227, doi:10.1016/ j.ympev.2006.11.013

—_ Matheny PB, Hibbett DS. 2005. Lower level relationships in the mushroom genus Cortinarius (Basidiomycota, Agaricales): a comparison of RPB1, RPB2 and ITS phylogenies. Mol Phylogenet Evol 37: 602-618, doi:10.1016/j.ympev.2005.06.016

Gardes M, Bruns TD. 1993. ITS primers with enhanced specificity for basidiomycetes-application to the identification of mycorrhizae and rusts. Mol Ecol 2:113-118, doi:10.1111/j.1365-294X.1993.tb00005.x

Garnica S, Spahn P, Oertel B, Ammirati J, Oberwinkler F. 2011. Tracking the evolutionary history of Cortinarius species in section Calochroi, with transoceanic disjunct distributions. BMC Evol Biol 11:213, doi:10.1186/14712148-11-213

— Weiß M, Oertel B, Ammirati J, Oberwinkler F. 2009. Phylogenetic relationships in Cortinarius, section Calochroi, inferred from nuclear DNA sequences. BMC Evol Biol 9:1, doi:10.1186/1471-2148-9-1

$\longrightarrow,-,-$, Oberwinkler F. 2003. Phylogenetic relationships of European Phlegmacium species (Cortinarius, Agaricales). Mycologia 95:1155-1170, doi:10.2307/3761917

- 2005. A framework for a phylogenetic classification in the genus Cortinarius (Basidiomycota, Agaricales) derived from morphological and molecular data. Can J Bot 83:1457-1477, doi:10.1139/b05-107

Gill M, Steglich W. 1987. Pigments of Fungi (Macromycetes). Progress Chem Org Nat Products 51:1-317.

Harrower M, Ammirati JF, Cappuccino AA, Ceska O, Kranabetter JM, Kroeger P, Lim S, Taylor T, Berbee ML. 2011. Cortinarius species diversity in British Columbia and molecular phylogenetic comparison with European specimen sequences. Botany 89:799810, doi:10.1139/b11-065

Huelsenbeck JP, Ronquist F. 2001. MrBayes: Bayesian inference of phylogenetic trees. Bioinformatics 17: 754-755, doi:10.1093/bioinformatics/17.8.754 
Jeppesen TS, Frøslev TG, Brandrud TE. 2008. Subgen. Phlegmacium (Fr.) Trog. In: Knudsen H, Vesterholt J, eds. Funga nordica-agaricoid, boletoid and cyphelloid genera. Copenhagen: Nordsvamp. p 680-720.

Katoh K, Misawa K, Kuma K, Miyata T. 2002. MAFFT: a novel method for rapid multiple sequence alignment based on fast Fourier transform. Nucleic Acids Res 30: 3059-3066, doi:10.1093/nar/gkf436

Melot J. 1990. Une classification du genre Cortinarius (Pers.) S.F. Gray. Doc Mycol 20:43-59.

Moser M, Ammirati JF. 1997. Studies on North American Cortinarii 4. New and interesting Cortinarius species (subgen. Phlegmacium) from oak forests in northern California. Sydowia 49:25-48.

Ortega A, Suárez-Santiago VN, Reyes JD. 2008. Morphological and ITS identification of Cortinarius species (section Calochroi) collected in Mediterranean Quercus woodlands. Fungal Divers 29:73-88.

Peintner U, Bougher NL, Castellano MA, Moncalvo JM, Moser MM, Trappe JM, Vilgalys R. 2001. Multiple origins of sequestrate fungi related to Cortinarius (Cortinariaceae). Am J Bot 88:2168-2179, doi:10. $2307 / 3558378$

—, Moncalvo JM, Vilgalys R. 2004. Toward a better understanding of the infrageneric relationships in Cortinarius (Agaricales, Basidiomycota). Mycologia 96: 1042-1058, doi:10.2307/3762088

Posada D. 2008. jModeltest: phylogenetic model averaging. Mol Biol Evol 25:1253-1256, doi:10.1093/molbev/ msn083
Rambaut A, Drummond AJ. 2007. Tracer 1.4. (http://beast. bio.ed.ac.uk/Tracer)

Ridgway R. 1912. Color standards and color nomenclature. Washington, DC: published by the author. $43 \mathrm{p}$.

Sontag B, Fröde R, Bross M, Steglich W. 1999. Chromogenic triterpenoids from Cortinarius fulvoincarnatus, $C$. sodagnitus and related toadstools (Agaricales). Eur J Org Chem 1999:255-260, doi:10.1002/(SICI) 10990690(199901) 1999:1<255::AID-EJOC255>3.0.CO;2-6

Stamatakis A. 2006. RAxML-VI-HPC: maximum likelihoodbased phylogenetic analyses with thousands of taxa and mixed models. Bioinformatics 22:2688-2690, doi:10.1093/bioinformatics/btl446

Tamura K, Peterson D, Peterson N, Stecher G, Nei M, Kumar S. 2011. MEGA5: Molecular evolutionary genetics analysis using maximum likelihood, evolutionary distance and maximum parsimony methods. Mol Biol Evol 28:2731-2739, doi:10.1093/molbev/msr121

Thiers B. 2011. [continuously updated]. Index herbariorum: a global directory of public herbaria and associated staff. New York Botanical Garden's Virtual Herbarium. (http://sweetgum.nybg.org/ih/)

Vizzini A, Contu M, Musumeci E, Ercole E. 2011. A new taxon in the Infundibulicybe gibba complex (Basidiomycota, Agaricales, Tricholomataceae) from Sardinia (Italy). Mycologia 103:904-911, doi:10.3852/10-382

White TJ, Bruns TD, Lee S, Taylor J. 1990. Amplification and direct sequencing of fungal ribosomal RNA genes for phylogenetics. In: Innis MA, Gelfand DH, Snisky JJ, White TJ, eds. PCR protocols. London: Academic Press. p 315-322. 